\title{
School Children as Health Agent: An Explorative Study on Peers' Perspectives
}

\author{
SM Suraiya ${ }^{1}$, B Pises $^{1}$, B Faizal $^{2}$, M Shahnaz $^{3} \&$ M Nor Asiah ${ }^{4,5}$ \\ ${ }^{1}$ Institute for Health Behavioural Research, Ministry of Health Malaysia, Jalan Rumah Sakit, Bangsar, 59000, \\ Kuala Lumpur, Malaysia \\ ${ }^{2}$ Institute for Medical Research, Ministry of Health Malaysia, Jalan Pahang, 50588, Kuala Lumpur, Malaysia \\ ${ }^{3}$ Office of Deputy Director General of Health (Research and Technical Support), Ministry of Health Malaysia, \\ Block E7, E Complex, Putrajaya Administrative Centre, 62590, Putrajaya, Malaysia \\ ${ }^{4}$ Non Communicable Disease Section, Level 2, Block E3, E Complex, Putrajaya Administrative Centre, 62590, \\ Putrajaya, Malaysia \\ ${ }^{5}$ Institute for Public Health, Ministry of Health Malaysia, Jalan Rumah Sakit, Bangsar, 59000, Kuala Lumpur, \\ Malaysia \\ Correspondence: Suraiya Syed Mohamed, Institute for Health Behavioural Research, Ministry of Health Malaysia, \\ Jalan Rumah Sakit, Bangsar, 59000, Kuala Lumpur, Malaysia. Tel: 603-2082-1400; Fax: 603-2284-9080. E-mail: \\ suraiya.sm@moh.gov.my; Nor Asiah Muhamad, Institute for Public Health, Ministry of Health Malaysia, Jalan \\ Rumah Sakit, Bangsar, 59000, Kuala Lumpur, Malaysia. Tel: 603-2282-1333; Fax: 603-22823114. E-mail: \\ sakinahnor@gmail.com,norasiahdr@gmail.com
}

Received: November 24, 2016 Accepted: January 4, 2017 Online Published: February 21, 2017

doi:10.5539/gjhs.v9n5p1 URL: https://doi.org/10.5539/gjhs.v9n5p1

\begin{abstract}
Introduction: School based programme known as 'Doktor Muda' was established to empower school children using their knowledge and health skills to achieve better health status. "Doktor Muda" (DM) is a group involved a selection of trained school children that met certain criteria as peer educators in order to influence their peers' attitude and health practices.
\end{abstract}

Methodology: A cross sectional study was carried out from March 2014 to January 2015. Qualitative data were collected by Focus Group Discussion (FGD) to identify peers perspective towards DM as a health promotion agent using a semi structured open ended questionnaire. The questionnaire was developed according to the relevant themes that identify the abilty of DM to influence their peers' attitude and health practices.

Results: The findings showed that majority of participants admitted positive response towards information given by $\mathrm{DM}$ in their behavioural beliefs towards health. Majority of the participants agreed DM has succeeded in changing their attitudes toward the importance of health involving were participants' concern on health. However, some of the participants claimed negative response showed by the peers during dissemination of information by DM and participants' observations. Verification from the feedback groups regarding individual who influence their personal hygiene practice revealed $45.5 \%$ by their ownself, $36.4 \%$ by their parents/family and $36.4 \%$ by DM respectively.

Conclusions: This study has succeeded in exploring peers' perspectives on the efficacy of DM as health promotion agent. Strengthening in positive beliefs among peers towards health, influencing positive attitudes to accentuate health and encouraging health practices at a moderate level were established in this study.

Keywords: Doktor Muda, peers' perspective, FGD, health promotion agent

\section{Introduction}

Health promotion is important in preventing comunicable and non communicable diseases including gastrointestinal and respiratory infections which normally transmitted by person to person contact and obviously school children are susceptible to this illnesses (Chittleborough, Nicholson, Young, Bell, \& Campbell, 2013). It will affect the child health in which they may miss educational opportunities and reduce the educational outcomes that involved productivity, increased absenteeism and days off work for school staff (Willmott et al., 2016). 
Previous studies also showed an association between educational interventions in school settings increased compliance with hand washing (Baxter \& Cleary, 2002; Early et al., 1998) will reduce respiratory infections. Generally health practices such as hand washing is a relatively simple method or ethique that is widely practice in every cultures and consider as important public health measure (World Bank, 2005). Promoting hand washing in school settings through participatory and practical methods has been studied in developed as well as in developing countries (Xuan, Rheinla"nder, Hoat, Dalsgaard, \& Konradsen, 2013).

\subsection{Malaysian Scenario}

According World Health Organization (WHO), health promotion is a process that empower people to take charge of health related issues and improve their health. The School Health Programme in Malaysia was developed in 1967 to provide health services and health education in schools (Ministry of Health, Malaysia [MOH], 2013a; $\mathrm{MOH}, 2008)$. In tandem with changes in health issues and disease trend, the needs to review the School Health Programme were required to enhance their roles to be more comprehensive. Hence, in 1996 an Intergrated School Health Programme was formed. The objective of Intergrated School Health Programme is to nurture positive attitude and healthy practices by increasing knowledge in personal hygiene, encourage healthy lifestyle and healthy school environment (MOH, 2013b). Intergrated approach was applied to collaborate between public, private sector, local and school community towards healthy school (MOH, 2012).

\subsection{Health Promotion Agent}

'Doktor Muda' (DM) programme was introduced as part of the Intergrated School Health Programme. DM programme is a school based programme aim to empower school children using the slogan "From Pupils, For Pupils, To Pupils" by increasing their knowledge and health skills to achieve better health status (Nasruddin, Omar, Ahmad, Wan Hussein \& Manaf, 2006). Thus, it also helps in assisting health personel conducting school health activities. DM is a group of selected school children that met certain criteria and were trained as club member or peer educators. Hence, this study aim is to determine DM abilities to influence their peers' attitude and health practices.

\section{Material and Methods}

\subsection{Study Design}

A cross sectional study was carried out from March 2014 to January 2015. Qualitative data were collected by Focus Group Discussion (FGD) to identify peers perspective towards DM as a health promotion agent.

A total of 26 (38\%) of 69 primary schools have established the clubs for DM in Gombak district, Selangor, Malaysia. This gave a total of 31, 072 pupils with 1,209 members as DM and 29,863 peers (statistic from District Health Office, Gombak). Of these, 12 schools have established the club for DM for more than three years. For this study, only Sekolah Kebangsaan Gombak Setia, Gombak, Selangor was selected for the qualitative analysis.

\subsection{Sampling Method}

A total of 194 pupils were eligible for the FGD session. From these, 70 pupils were selected through systematic random sampling (Fisher Random Number). Only pupils aged 11 years old who have been in the school for more than 2 years with parents consent and present during the FGD session were included in this study.

\subsection{Data Collection}

Data were collected between September and October 2014. There was no incentive given to the participants but breakfasts were provided before the FGD sessions. Seven sessions of FGD were held with each session involving 10 participants, which in total a sampel of 70 participants with equal gender balance. All FGD sessions were conducted in Malay language that last for 60 to 90 minutes.

A trained moderator conducted the FGD session using a protocol containing information on self introduction, introduction to note taker, explanation on the information that is going to be extracted through video and audio recording, field notes and reason for the subject selection. Along with this information, the purpose of study and cooperation from the participants and confidentiality were explained.

All FGD sessions were conducted using a semi structured open ended questionnaire. The questionnaire was developed according to the relevant themes that identify the abilty of DM to influence their peers' attitude and health practices (Chua, 2011). Each FGD session was audio recorded and transcribed verbatim. Video recording were used to identify non verbal communication and group interaction to support the field notes by the note taker (Hennink, 2007). The moderator used dynamic group techniques such as visual aids, scale rating, listing and ranking to encourage discussion and minimize domination by members of the group during FGD session (Johnson 
\& Christensen, 2004).

The semi-structured questionnaire was divided into 5 parts including:

1) Ice-breaking - to make the participants comfortable with each other before starting the discussion. The moderator has used perception visual to encourage the participants to response and interact freely.

2) Introduction - warming up and screening questions to ensure how far the participants know DM. Then the questions will lead to general questions that introduce participants to the topic of study.

3) Transition- questions involved participants' attention in gathering the health activities information by DM.

4) Main question - related to credibility of DM as health promotion agent including the abilities of DM in changing positive attitude and influence peers towards healthy lifestyle. Participants were asked whether they are comfortable discussing health issues with DM. Participants were also asked about credibility characteristics of DM.

5) Closing- Finally, in this section, participants was asked to rate from 1 to 10 the effectiveness of DM as health promotion agent and their interest to become members (Glanz, Rimer, \& Lewis, 2002).

In this explorative study based on grounded theory, new information from every FGD session was used to enrich the questions for the next FGD session (Johnson \& Christensen, 2004). Hence, there was improvement in the questions asked until it reached saturated point where no additional information was found (Mack, Woodsong, MacQueen, Guest, \& Namey, 2005).

\subsection{Ethical Approval}

Ethical approval was obtained from the Planning and Research Education Policy, Ministry of Education, Malaysia and Medical Research Ethics Committee, Ministry of Health, Malaysia. Written consents were obtained from the parents prior to the interview.

\subsection{Data Management and Analysis}

Data were analysed using triangulation technic to cross-checked between primary and secondary data (Mack et al., 2005). Primary data involving recorded tapes from focus group discussion were transcribed together with field notes, observation notes and video recordings. Informal interview between principal investigator, DM club adviser and programme coordinator were also documented. As for secondary data, list of schools with DM club, reten activities, list of health problems in Gombak schools and name list of year 5 in SK Gombak Setia were retrieved in our records.

Qualitative data analysis was a continuous process beginning with data collection until report writing. Data were analysed systematically in order to reduce bias in selection and to ensure the quality of the research (Flick, 2007). Thematic analysis was used to analyze the qualitative data in this study. The materials were read thoroughly several times before key words and themes were indentified and coded. The coding differences were resolved through thorough discussions to ensure all perspectives on the themes were represented. Content analysis was performed and verified by a feedback group that represented all FGD groups.

\section{Results}

The findings are presented according to themes identified: (i) behavioural beliefs towards health, (ii) attitudes towards health (iii) health practices. Verbatim quotes are labelled according to response by the participants to support findings:

\section{(i) Behavioural beliefs towards health}

Participants' assessment of positive belief in behavior is translated as pay attention, whereby negative belief of behavior is as less or no attention to message delivery by DM. Finding shows majority of participants admitted positive response towards information given by DM such as listening and observing carefully, silence and taking notes during message delivery. Negative reasons by the participants referred to "self-defense" such as already know about the matters, complaining on tiredness, disturbed by peers. This was shown by following quotes:

Girls: "Write in the note book...so it can be practiced at home."

Boys: "So that I can teach other people ...tell others... and correct them when they make mistake like when they don't wash hands before eating."

Moderator: "Did all of you pay attention?" 
Boys: "Not really.."

Girls: "No...my legs feel tired...."

However, according to participants more than $50 \%$ of their peers hardly give attention to DM by interrupting during the session. Participants' opinion of their peers who do not pay attention as "presumption" associated with a negative attitude for not trusting the health information given by DM who had grown up with them.

\section{(ii) Attitudes towards Health}

Attitudes toward health were measured from abilities of DM in changing negative to positive attitudes of their peers about the importance of health. These positive attitudes were influenced by participants' positive beliefs or evaluation on positive behavior outcome, hence will lead to intention in practicing good health practice and vice versa.

Majority of the participants agreed DM succeeded in changing their attitudes toward the importance of health involving were participants ' concern on health. Some of the participants claimed that they neglected the health practices because of in hurry and forgetfulness. However, a few participants admitted they were not interested in practicing good health. Verification from feedback group confirmed the results as $91.0 \%$ agreed DM has positive influence among participants on the importance of health.

This study also showed that subject's has different opinion on the ability of DM in changing the attitudes of their peers towards the importance of health. They assumed that their peers were not interested in health matters that related to negative response showed by the peers during dissemination of information by DM and participants' observations. This was reflected on the following quotes:

Girls: "Because she thinks personal hygiene is boring...even when it comes to cleanliness also they will ignore." Boys: "They don't like to listen to health talk."

\section{(iii) Health Practices}

Majority of the participants admitted that they followed DM advice on health practices and activities. Only few participants seldom follow DM`s advice whereas among peers more than half of them neglected DM's advice on health. The following quotes were reflected on practices adviced by DM:

Girls: "I follow, so that they know how to do the right way."

Boys: "Yes! Because last time we brushed our teeth the different way."

(Other participants added): "He taught us how to do it."

Boys: "Use soap, (other participants added); Previously we only used water to wash hand"

Moderator: "When you know that health is important, will you practice it?"

Boys: "Sommetimes." (Other participants added) "Almost all don't do it..."

Girls: "Not necessarily, we forgot, sometimes we are lazy, sometimes we are in the hurry so can 't do it."

This study found that verification from the feedback groups regarding individual who influence their personal hygiene practice revealed $45.5 \%$ by their ownself, $36.4 \%$ by their parents/family and $36.4 \%$ by DM respectively. The findings were strengthened by using listing and ranking techniques where the sequence according to priority were parents/family (1.7), medical doctor (1.8), DM (2.1) and teachers (2.7). Overall, 8 (72.7\%) participants agreed, $2(18.2 \%)$ not sure dan $1(9.1 \%)$ did not agreed that DM has an influence on their health practices.

\subsection{Rating on the Effectiveness of Health Information Delivery}

The results showed 47 (67.1\%) participants gave high rating between 8 to 10 and 23 (32.9\%) gave average rating between 5 to 7. Details of the rating are presented in Table 1. Comparison between genders showed $30(63.8 \%)$ female participants gave higher rating compared to male, 17 (36.2\%). Comparison between classes (5C and 5E) gave average rating. These results consistent with the findings on communication barriers stated by participants regarding gender differences as supported by the following quotes:

"Why are the boys gave average marks on DM?" (MODERATOR) "Because DM is a female.....There are males and females, but more females. (5E: Boys) 
Table 1. Rating on the Effectiveness of Health Information Delivery by D

\begin{tabular}{|c|c|c|c|c|c|c|c|c|c|c|c|c|c|c|c|}
\hline FGD & & & $5 \mathrm{AA}$ & & 5B & & $5 C$ & & 5D & & $5 E$ & & $5 F$ & & \\
\hline Rating & $\mathbf{M}$ & $F$ & $\mathbf{M}$ & $\mathbf{F}$ & $\mathbf{M}$ & F & M & $F$ & $\mathbf{M}$ & F & M & F & $\mathbf{M}$ & $F$ & $\mathbf{N}$ \\
\hline 5 & 3 & 1 & & & & & 3 & 1 & & & 1 & & & & 9 \\
\hline 6 & 2 & & & & & & 2 & & & & 2 & & & & 6 \\
\hline 7 & & 1 & 1 & 1 & 2 & & & 1 & & & 2 & & & & 8 \\
\hline 8 & & 1 & 3 & 3 & 2 & & & 1 & 2 & & & 4 & 1 & & 17 \\
\hline 9 & & 2 & 1 & 1 & 1 & 4 & & 2 & & 1 & & & & & 12 \\
\hline 10 & & & & & & 1 & & & 3 & 4 & & 1 & 4 & 5 & 18 \\
\hline $\mathbf{N}$ & 5 & 5 & 5 & 5 & 5 & 5 & 5 & 5 & 5 & 5 & 5 & 5 & 5 & 5 & 70 \\
\hline
\end{tabular}

\section{Discussion}

The impact of DM as health agent is dictated by the ability of DM to influence beliefs, attitudes and practices of their peers on health (Kirby, 2001). Positive beliefs towards model behaviour are translated into better sustained attention, whereas negative beliefs on behaviour manifest into less attentiveness towards health information delivered by DM (Borgia, Marinacci, \& Schifano, 2005; Bloor et al., 1999). In short, how peers perceive the importance of health is directly correlated to the amount of attention they pay to the knowledge disseminated to them by DM (Falchikov, 2001; Fenella, Audrey, Holliday, Moore, \& Campbell, 2009).

In this study`s context, the conviction of peers on the importance of health is indeed translated into the amount of attention they pay to health information delivered by DM. Unfortunately, there are still several among them that pay little to no attention but this is not attributed to the lack of their principle on the importance of health, but rather, certain barriers along the lines of communication (Klepp, Halper, \& Perry, 1986). This research finding validates previous research results that the DM delivering messages about health received a poor feedback from their peers such that over $60 \%$ in Negeri Sembilan $(\mathrm{MOH}, 2013 \mathrm{~b})$ and over $80 \%$ in Kuala Selangor were attributed to communication skills (Azimah, 2014).

Participants observe peers who do not emphasize their health and well-being and find that these cohorts are nonchalant about health and they are not attentive towards the information dissemination sessions- reasons which can be caused by barriers in communication (Nasruddin, Omar, Ahmad, Wan Hussein, \& Manaf; 2006). For instance, participants in class $5 \mathrm{~F}$ that do not pay attention and thought to be indifferent about their health by other participants have actually refuted this and claimed that they do value their health and follow the advice given by DM about personal hygiene and help spread knowledge to their family members. Hence, these participants stated that their lack of attention is simply a result of communication barriers that occur during their information session with DM in a non-conducive environment (Stock et al., 2007; Truong, 2008; Venditti et al., 2014).

According to Social Learning Theory, to enable effective learning, one has to be attentive towards an exemplary model (Bandura, 1977). Any disruption upsetting the individual's focus will cause a negative impact on observational learning. If the model was interesting or the activities are stimulating, then the probability of the learner giving his or her full attention is higher (Ajzeen \& Fishbein, 1977). Hence, this relates to the selection of $\mathrm{DM}$ as well as utilising the best method of communication that fulfils the learning objectives and intrigues peers simultaneously (Guldal, Mesvim, Gunvar, \& Ozcakar; 2012).

A long period had lapsed since health information from DM was disseminated, such that several participants encountered difficulties in recalling exact details (problems in retaining information). Therefore, information has to be repeated in an interesting way to refresh peers' memories (McDonald, Grove, \& Forum of Advisory member, $2000,2001)$. In addition, they have to re-enact the actions they observe. The competency of performing these actions and applying them will improve their skills dramatically (Mckenzie, Neiger, \& Thackeray, 2009). However, in the context of this study, the demonstration techniques used by DM does not provide space or opportunity for peers to demonstrate if they truly have understood what they just observed (Flanagan, Williams, \& Mahler, 1996).

According to Bandura (1977), for successful observational or adaptive learning, peers have to be motivated to re-enact what they learned. Reinforcement in the form of rewards like compliments or gifts, and penalties like warnings or precautions can play a vital role in motivating them (Flanagan, Williams, \& Mahler, 1996). In this programme, awarding gifts for answering quizzes correctly are seldom done (less motivation to perform well). In 
fact, constructive advices by DM to the peers who do not practise healthy lifestyles are rarely done and not consistent.

In this study the conviction that health matters and shaping positive attitude towards it is not solely a direct cause of DM's efforts. This belief has been embedded early in life by parents, family members, teachers and health societies in schools as well as their schooling environment, considering that personal and oral hygiene are widely taught in every school. Hence, the health information sessions delivered by DM serve as reinforcement of peers' established beliefs on the importance of health and thus form positive attitude towards it.

According to Azjen (1991), one's attitude towards behaviour is in fact either a positive or negative evaluation made by an individual towards said behaviour. An example of factors that determine attitude is one's belief towards behaviour. In this study, positive attitude about health among peers is influenced by positive beliefs or the evaluation that behaviour will produce positive outcomes. For example, the act of brushing teeth correctly will prevent oral disease (Caccamo, 2000). Conversely, an aloof view on health is influenced by negative beliefs or judging behaviour to be unproductive (Griebler, Rojatz, Simovska, \& Forster, 2014). One example would be certain individuals believing that brushing teeth as often as suggested by DM is unhelpful because they deem it to be time-consuming or simply because they are lazy.

All in all, DM has succeeded in changing the participants' attitude to be more health conscious, but this only applies to less than half of their peers (Lotrean, Dijk, Mesters, Ionut, \& De Vries, 2010). This could be due to negative attitudes formed by their creed that these health practices can be abandoned from time to time because it would not have a substantial impact. It is also possible that some of them may already have a positive outlook, but their negative behaviour of neglecting health practices or not adhering to a healthy lifestyle is due to human nature of forgetfulness and the need for constant reminders (Konu, Lintonen, \& Rimpelä, 2002).

The findings of this study also state that overall, DM is successful in influencing health practices of the participants, but only in less than half of their peers. Health practices that the majority of participants adhere to relate to personal hygiene like frequency of brushing teeth and the proper way of doing so. This has been instilled from an early age by parents but is now being rehashed by DM to serve as a reminder on the importance of brushing teeth adequately.

Verification was obtained from feedback group that concluded that almost half of all participants practice good hygiene because of personal reasons, parental influence or family influence and of course, DM. And also there are different levels of influence possessed by cohorts that affect heath practices in participants which include parents/family, medical doctors, DM and teachers (Medley, Kennedy, \& O'Reilly, 2009). Pressure from society has a role too, and in particular, pressures from parents and DM in solidifying personal hygiene. Obeying health practices among participants is further strengthened by the spread of health information to family members and peers as a result of a combination of faith, attitude and positive health practices (Mellanby, Rees, \& Tripp, 2000; Michielsen et al., 2012).

Overall, there is a distinct and consistent connection between positive beliefs about behaviour (attentiveness), building positive attitude (prioritising health) and subsequently leading to positive practices (following health practices) among participants (Samdal, Nutbeam, Wold, \& Kannas, 1998). Conversely, negative beliefs about behaviour (inattention), can influence negative attitude (indifferent to health) and therefore lead to negative practices (neglecting health practices) among participants (Kirby, 2001; Mason, Flisher, \& Mathews, 2011). However, participants who are inattentive should not be considered as neglecting their health. Similarly, participants that claim to be health conscious do not necessarily adhere to healthy practices (Newton \& Ender, 2010; Rimer \& Glanz, 2005).

The effectiveness of the health information-giving session by DM that was assessed using a rating system provides an overview that DM is successful in playing its part as health-promoting agents (Simovska \& Carlsson, 2012). Most participants agree that DM activities are fun, good in raising awareness in participants to be more health conscious and can be incorporated into daily living.

\section{Conclusions}

DM can be used to improve the school health promotion and create positive beliefs among peers towards health, influencing positive attitudes to accentuate health and consequently, encouraging health practices at a moderate level. Obeying health practices among participants was also reinforced by spreading health information to family members which results from a blend of faith, attitude and positive health practices (Starkey, Audrey, Holliday, Moore \& Campbell, 2009). Participants' interests on becoming a member of DM themselves also showcase the positive impact of this programme. Training of school children as health agent should be strengthened to inculcate healthy lifestyle among children in school. Further studies need to be done to identify the barriers and challenges to 
achieve sustainability of the programme.

\section{Funding}

There was no funding for this research.

\section{Competing Interests Statement}

The authors declare that there is no conflict of interests regarding the publication of this paper.

\section{References}

Ajzeen, I. (1991). The Theory of Planned Behaviour. Organizational behaviour and human decision process, 50, 179-211. https://doi.org/10.1016/0749-5978(91)90020-T

Ajzeen, I., \& Fishbein, M. (1977). Attitude behavior-relation: A theoretical analysis and review of empirical research. Psychology Bulletin, 84, 888-918. https://doi.org/10.1037/0033-2909.84.5.888

Azimah, M. S. (2014). Message Delivery by 'Doktor Muda' in National-Type School in Kuala Selangor. (Unpublished master's thesis). Universiti Kebangsaan Malaysia, Malaysia.

Bandura, A. (1977). Social Learning Theory. Prentice-Hall, Englewood Cliffs, NJ.

Baxter A., \& Cleary V. (2002). Hand hygiene in local primary school children — an infection control and health promotion initiative. Br J Infect Control, 3, 14-17.

Bloor, M., Frankland, J., Parry Langdon, N., Robinson, M., Allerston, S., Catherine, A., ... Spragg B. (1999). A controlled evaluation of an intensive, peer-led, schools-based, anti-smoking programme. Health Education J., 58, 17-25. https://doi.org/10.1177/001789699905800103

Borgia, P., Marinacci, C., \& Schifano, P. (2005). Is peer education the best approach for HIV prevention in schools? Findings from a randomized controlled trial. $J$. Adolescent Health, 36, 508-16. https://doi.org/10.1016/j.jadohealth.2004.03.005

Caccamo, J. M. (2000). Sharing the vision: Healthy achieving students. J. of School Health, 70(5), 216-218. https://doi.org/10.1111/j.1746-1561.2000.tb06477.x

Chittleborough C. R., Nicholson, A. L., Young, E., Bell, S., \& Campbell, R. (2013). Implementation of an educational intervention to improve hand washing in primary schools: process evaluation within a randomised controlled trial. BMC Public Health, 13, 757. https://doi.org/10.1186/1471-2458-13-757

Chua, Y. P. (2011). Book 1: Research Methodology. McGraw-Hill (Malaysia) Sdn Bhd., Kuala Lumpur.

Early, E., Battle, K., Cantwell, E., English, J., Lavin, J. A. E., \& Larson, E. (1998). Effect of several interventions on the frequency of handwashing among elementary public school children. Am J Infect Control, 26, 263-269. https://doi.org/10.1016/S0196-6553(98)80011-4

Falchikov, N. (2001). Learning together: Peer tutoring in higher education. Routledge-Falmer, Tyler \& Francis Group UK, London. https://doi.org/10.4324/9780203451496

Fenella, S., Audrey, S., Holliday, J., Moore, L., \& Campbell, M. (2009). Identifying influential young people to undertake effective peer-led health promotion: the example of A Stop Smoking In Schools Trail (ASSIST). Health Education Research, 24(6), 977-988. https://doi.org/10.1093/her/cyp045

Flanagan, D., Williams, C., \& Mahler, H. (1996). Peer education in projects supported by AIDSCAP: a study of 21 projects is Africa. Asia and Latin America. Washington, DC: Family Health International, Academy for Educational Development. IDSCAP/FHI.

Flick, U. (2007). Designing qualitative research: The SAGE Qualitative Research Kit. SAGE Publications. London. https://doi.org/10.4135/9781849208826

Glanz, K., Rimer, B. K., \& Lewis, F. M. (2002). Health behavior and health education: theory, research and practice (3rd Ed.). San Francisco: Jossey-Bass A Wiley Imprint.

Griebler, U., Rojatz, D., Simovska, V., \& Forster, R. (2014). Effects of student participation in school health promotion: A systematic review. Health Promotion Int. 2014 [E-pub ahead of print]. Retrieved from https://doi.org/10.1093/heapro/dat090

Guldal, D., Mesvim, V., Gunvar, T., \& Ozcakar, N. (2012). The perspective of peer educators: what are their experiences, feelings, and thought? Health Journal, 4(7), 349-356. https://doi.org/10.4236/health.2012.47057 
Harris, J., \& Cale, L. (1997). How healthy is school PE? A review of effectiveness of health-related physical education programmes in schools. Health Education J., 56, 84-104. https://doi.org/10.1177/001789699705600109

Hennink, M. M. (2007). International focus group research: A handbook for the health and social sciences. Cambridge University Press. UK. https://doi.org/10.1017/CBO9780511619458

Johnson, B., \& Christensen, L. (2004). Educational research: Quantitative, qualitative, and mixed approaches (2nd ed.). Boston: Pearson Education, Inc.

Kirby, D. (2001). Understanding what works and what doesn't in reducing adolescent sexual risk taking. Fam Plann Perspect, 33, 276-81. https://doi.org/10.2307/3030195

Klepp, K. I., Halper, A., \& Perry, C. L. (1986). The efficacy of peer leaders in drug abuse prevention. J. of School Health, 56, 407-411. https://doi.org/10.1111/j.1746-1561.1986.tb05783.x

Konu, A. I., Lintonen, T. P., \& Rimpelä, M. K. (2002). Factors associated with school children's general subjective well-being. Health Education Research, 17(2), 155-165. https://doi.org/10.1093/her/17.2.155

Lotrean, L. M., Dijk, F., Mesters, I., Ionut, C., \& De Vries, H. (2010). Evaluation of a peer-led smoking prevention programme for Romanian adolescents. Health Education Research, 25(5), 803-814. https://doi.org/10.1093/her/cyq034

Mack, N., Woodsong, C., MacQueen, K. M., Guest, G., \& Namey, E. (2005). Qualitative research methods: A data collector's field guide. Family Health International \& USAID. USA.

Mason, A. J., Flisher, A. J., \& Mathews, C. (2011). Who are peer educators? HIV prevention in South African schools. Health Education Research, 26(3), 563-571. https://doi.org/10.1093/her/cyq064

McDonald, J., Grove, J., \& Youth Advisory Forum Members. (2001). Youth for Youth: Piercing together the peer education jigsaw. Proceedings of the 2nd International conference on drugs and young people exploring the bigger picture. Melbourne.

McDonald, J., Grove, J., \& Youth Advisory Forum Members. (2000). Youth for Youth: A project to develop skills and resources for peer education: Final Report. Adelaide.

Mckenzie, J. F., Neiger, B. L., \& Thackeray, R. (2009). Planning, implementing \& evaluating health promotion programs: A primer (5th ed.). Pearson International Edition.

Medley A., Kennedy C., O'Reilly K. (2009). Effectiveness of peer education interventions for HIV prevention in developing countries: a systematic review and meta-analysis. AIDS Educ Prev., 21,181-206. https://doi.org/10.1521/aeap.2009.21.3.181

Mellanby, A. R.., Rees, J. B., \& Tripp, J. H. (2000). Peer-led and adult-led school health education: A critical review of available comparative research. Health Education Research Theory \& Practice., 15(5), 533-545. https://doi.org/10.1093/her/15.5.533

Michielsen, K., Beauclair, R., Delva, W., Roelens, K., Van Rossem, R., \& Temmerman, M. (2012). Efectiveness of a peer-led HIV prevention intervention in secondary schools in Rwanda: Results from a non-randomized controlled trial. BMC Public Health, 12, 729. https://doi.org/10.1186/1471-2458-12-729

Ministry of Health, Malaysia. (2008). 'Doktor Muda' Club Training Module. 3rd Edition. Health Education Division, Ministry of Health, Malaysia.

Ministry of Health, Malaysia. (2012). Global school-based student health survey: fullreport. Institute for Public Health, Ministry of Health, Malaysia.

Ministry of Health, Malaysia. (2013a). 'Doktor Muda'Club Training Module (4th ed.). Health Education Division, Ministry of Health, Malaysia.

Ministry of Health, Malaysia. (2013b). Study on Message Delivery by 'Doktor Muda`in Negeri Sembilan (Report). Institute for Health Behavioural Research Ministry of Health, Malaysia.

Nasruddin, J., Omar, K, Ahmad, J., Wan Hussein, W. S., \& Manaf, Z. A. (2006). The "Doktor Muda" health promotion program: A process evaluation. Seameo Library.

Newton, F. B., \& Ender, S. C. (2010). Students helping students: A guide for peer educators on college campuses. John Wily \& Sons.

Rimer, B. K., \& Glanz, K. (2005). Theory at a glance: a guide for health promotion practice. U.S. Department of 
Health \& Human Services, National Institutes of Health.

Samdal, O., Nutbeam, D., Wold, B., \& Kannas, L. (1998). Achieving Health and Educational Goals through Schools - a Study of the importance of the school climate and the students' satisfaction with school. Health Education Research, 13(3), 383-397. https://doi.org/10.1093/her/13.3.383

Simovska, V., \& Carlsson, M. (2012). Health promoting changes with children as agents: findings from a multiple case study research. Health Education, 112, 292-304. https://doi.org/10.1108/09654281211217803

Starkey, F., Audrey, S., Holliday, J., Moore, L., \& Campbell, R. (2009). Identifying Influential young people to undertake effective peer-led health promotion: the example of A Stop Smoking In Schools Trial (ASSIST). Health Education Research, 24(6), 977-988. https://doi.org/10.1093/her/cyp045

Stock, S., Miranda, C., Evans, S., Plessis, S., Ridley, J., Yeh, S., \& Chanoine, J. P. (2007). Healthy buddies: A novel, peer-led health promotion program for the prevention of obesity and eating disorders in children in elementary school. Pediatrics, 12(4), 1059-1068. https://doi.org/10.1542/peds.2006-3003

World Bank. (2005). The Global Public Private Partnership for Handwashing: The Handwashing Handbook. A guide for developing a hygiene promotion program to increase handwashing with soap. Washington DC

Truong, J. (2008). Peer education: a viable approach for reaching youth. Baltimore, MD: Global Health Technical Briefs: USAID.

Venditti, E. M., Giles, C., Firrell, S. L., Zeveloft, A. D., Hirst, K., \& Marcus, M. D. (2014). Interactive learning activities for the middle school classroom to promote healthy energy balance and decrease diabetes risk in the HEALTHY primary prevention trial. Health Promotion Practice, 15(1), 55-62. https://doi.org/10.1177/1524839912469377

Willmott, M., Nicholson, A., Busse, H., MacArthur, G. J., Brookes, S., \& Campbell, R. (2016). Effectiveness of hand hygiene interventions in reducing illness absence among children in educational settings: A systematic review and meta-analysis. Arch Dis Child, 101, 42-50. https://doi.org/10.1136/archdischild-2015-308875

Xuan, L. T., Rheinländer, T., Hoat, L. N., Dalsgaard, A., \& Konradsen, F. (2013). Teaching handwashing with soap for schoolchildren in a multi-ethnic population in northern rural Vietnam. Glob Health Action, 6, 20288. https://doi.org/10.3402/gha.v6i0.20288

\section{Copyrights}

Copyright for this article is retained by the author(s), with first publication rights granted to the journal.

This is an open-access article distributed under the terms and conditions of the Creative Commons Attribution license (http://creativecommons.org/licenses/by/4.0/). 